\title{
A Medico Legal Study of Hanging Cases at Dhaka Medical College
}

\author{
M Ahmad ${ }^{1}$, F N Rahman², M A Hussain ${ }^{3}$, M H Chowdhury ${ }^{4}$, B H N Yasmeen ${ }^{5}$
}

${ }^{1}$ Lt. Col (Dr.) Mushtaq Ahmad MBBS, MCPS, DFM

Associate Professor (Classified Specialist) \& Head Dept. of Forensic Medicine Armed Forces Medical College, Dhaka

2

Dr. Farial Naima Rahman MBBS, DMU

Lecturer, Dept. of Forensic Medicine Armed Forces Medical College, Dhaka

${ }^{3}$ Prof. Dr. Md. Anwar Hussain MBBS, MCPS

Principal \& Head

Dept. of Forensic Medicine \& Toxicology Northern International Medical College Dhaka

${ }^{4}$ Prof. Dr. Md. Habibuzzaman Chowdhury MBBS, DFM, MCPS

Professor \& Head

Dept. of Forensic Medicine Dhaka Medical College, Dhaka

${ }^{5}$ Prof. Dr. B H Nazma Yasmeen

Professor \& Head

Dept. of Paediatrics

Northern International Medical College

Dhaka

\section{Correspondence}

Lt. Col ( Dr.) Mushtaq Ahmad

MBBS, MCPS, DFM

Associate Professor

(Classified Specialist) \& Head

Dept. of Forensic Medicine

Armed Forces Medical College, Dhaka

E-mail : mushtaq863@yahoo.com

\section{Abstracts :}

This retrospective study was conducted among 574 Autopsy cases of hanging victims at the Dhaka Medical College Morgue during the period January 2008-December 2009.

Objective : The objective of this study was to find out the physical charecteristics, cause, place as well as the injuries specially in neck structures, variation of ligature materials, ligature marks, position of knot in the study subjects.

Methods : A total of 5114 autopsies were performed during the study period, out of which 574(11.22\%) were hanging cases. Ligature strangulation and manual strangulation cases were excluded from this study.

Various Data of this hanging victims regarding places of incidence, time, suspected causes of death (related information were gathered from the victims attendants), type of suspension were noted from the inquest report accompanying the dead bodies. Points regarding ligature material, position of knot, pattern of ligature marks, injury to neck structures, fracture of hyoid bone and thyroid cartilages were collected from the $3^{\text {rd }}$ copy of post mortem reports preserved in the Forensic Medicine \& Toxicology Department of DMC. Finally data were analyzed and presented in table,graph and in pie chart.

Results : Out of 574 hanging cases female were predominant (72.29\%). Among them 304( 52.96\%) were married. Marital disharmony/quarrel between couples was the main cause $172(29.96 \%)$ of hanging. Most of the victims 269(46.86\%) were in the age group 21-30 years.Dopatta (orna) was the commonest 237(41.28\%) ligature material. Considering the knot, most were situated at right side of neck 281 ( 48.95\%).In this study single ligature mark has been found in $511(89.02 \%)$ cases and was non continuous in 478(83.27\%) study subjects. In 520(90.59\%) cases ligature was found above thyroid cartilage level. The mark was oblique in 509(88.68\%) cases and impression corresponding to ligature material found in $126(21.95 \%)$ cases. Considering injury to neck structures most of them $448(78.04 \%)$ had stretching and elongation of neck, haemorrhage in underlying layers of neck skin in 372(64.81\%). Injury to the other structures of neck were variable. Most of the victims $401(69.86 \%)$ hanged themselves at night. 545 body $(94.95 \%)$ were recovered from inside the living room.
Most victims had complete suspension 472 (82.23\%).

Conclusion : This retrospectivemedico legal study find out various data of hanging victims of one of the largest heath care center, Dhaka Medical College, which cover a large area of population. Though multi center prospective study should be carried out to find out our real situation.

Key Words : Hanging, Autopsy, Neck structure injury.

\section{Introduction}

Hanging, the most common method of suicide is a form of violent asphyxial death in which the body is suspended by a ligature material which constricts the neck structures and prevents entry of air into lungs, the constricting force being the weight of the body ${ }^{1}$. It produces painless death for the victims and there is no costs involvement other than that of the ligature material. A thin jute rope around the neck will cause unconsciousness in 15 seconds $^{3}$. So the people prefer it as a common method of suicide in our country. These methods are also followed in other south Asian countries ${ }^{4-5}$. A good number of people commit suicide each year, making it one of the 10 leading causes of death in the world accounting more than a million death annually ${ }^{6}$. Even in developed countries like Serbia, Norway or Hungary suicide by hanging cases are commonly found. ${ }^{7-9}$ In England and Wales hanging is the commonest method of suicide, accounting 2000 deaths each year. ${ }^{10}$

During hanging the body completely suspends from above without touching the ground, which is called complete hanging, sometimes some parts of body touches the ground, this is called incomplete or partial hanging ${ }^{2}$. The position of knot in neck is very important because it can cause unequal pressure on the neck resulting different injuries to neck structures. In complete hanging injuries are more than partial hanging, where the body weight is supported by ground. 
Fracture of hyoid bone and thyroid cartilage are of important pathogenesis to forensic specialists specially when death is caused by neck constriction in hanging or manual constriction or homicide by strangulation.

\section{Materials and method}

This retrospective study was conducted among victims of hanging at the Dhaka Medical College Morgue during the period January 2008- December 2009. Various data of the victim along with places of incidence, time, suspected causes of death, type of suspension andother related information were gathered from the victim's attendants were noted from the inquest report accompanying the dead bodies. Points regarding ligature material, position of knot, pattern of ligature marks, injury to different neck structures (fracture of hyoid bone and thyroid cartilages were determined by visual and palpatory method) etc were noted during post mortem examinations.

Therefore all data related to these were collected from the $3^{\text {rd }}$ copy of post mortem reports preserved in the Forensic Medicine \& Toxicology Department of Dhaka Medical College. Ligature strangulation and manual strangulation cases were excluded from this study. Finally all data were analyzed and presented in table, graph and in pie chart.

\section{Results}

Out of 574 hanging cases female were predominant (72.29\%). Male were 9(27.71\%). Among them 304( 52.96\%) were married and $270(47.04 \%)$ were unmarried. Marital disharmony/quarrel between couples was the main cause $172(29.96 \%)$ behind hanging. Other causes were Mental depression, Drug addiction, Failure in love affairs, Unwanted pregnancy, Incurable disease, Mentally imbalance and Various family problems (Table-I).

Table-I : Suspected causes of hanging $(n=574)$

\section{Suspected causes of hanging}

Total

Marital disharmony/ quarrel between couples

Various family problems

$85(14.81 \%)$

Mental depression

$77(13.42 \%)$

Drug addiction

$65(11.32 \%)$

Failure in love affairs

$47(8.19 \%)$

Unwanted pregnancy

$37(6.44 \%)$

Incurable disease

23(4.01\%)

Mentally imbalance

$17(2.96 \%)$

$51(8.89 \%)$

Most of the victims 269( 46.86\%) were in the age group 21- 30 years ( Fig-l).

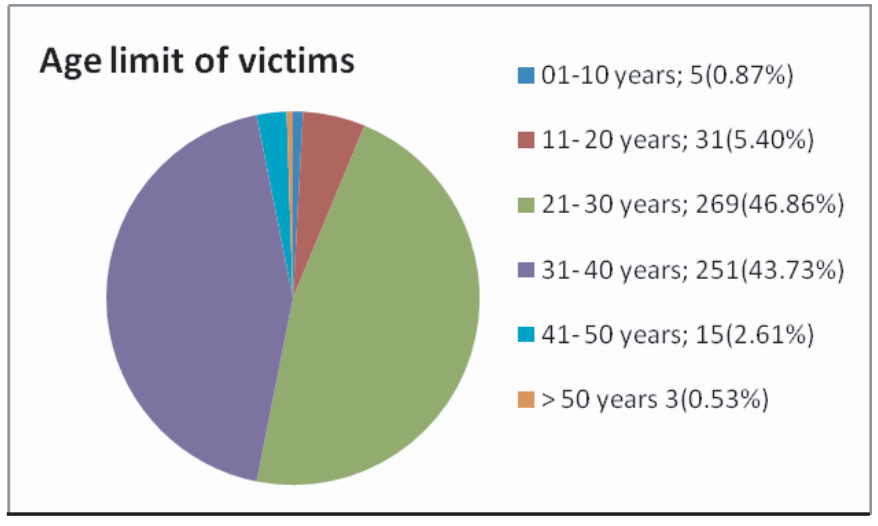

Fig-1 : Variation of age of hanging victims $(n=574)$

Dopatta (orna) was the commonest $237(41.28 \%$ ) ligature material followed by jute rope $195(33.97 \%)$ and shari 42(7.32\%) ( Table-II).

$\begin{array}{lc}\begin{array}{l}\text { Table-II : Ligature materials used for hanging }(\mathbf{n}=\mathbf{5 7 4}) \\ \text { Variation of ligature materials }\end{array} & \text { Total } \\ \text { Orna ( dopata) } & 237(41.28 \%) \\ \text { Jute rope } & 195(33.97 \%) \\ \text { Shari } & 42(7.32 \%) \\ \text { Nylon rope } & 28(4.88 \%) \\ \text { Lungi/ dhuti } & 25(4.35 \%) \\ \text { Kamiz } & 21(3.68 \%) \\ \text { Electric wire } & 03(0.52 \%) \\ \text { Other materials } & 23(4.00 \%)\end{array}$

Considering the knot, most were situated at right side of neck $281(48.95 \%)$, followed by left side 235 ( 40.94\%), at the nape of neck $50(8.71 \%)$ and in front of neck below chin $8(1.39 \%)$ (Fig-2).

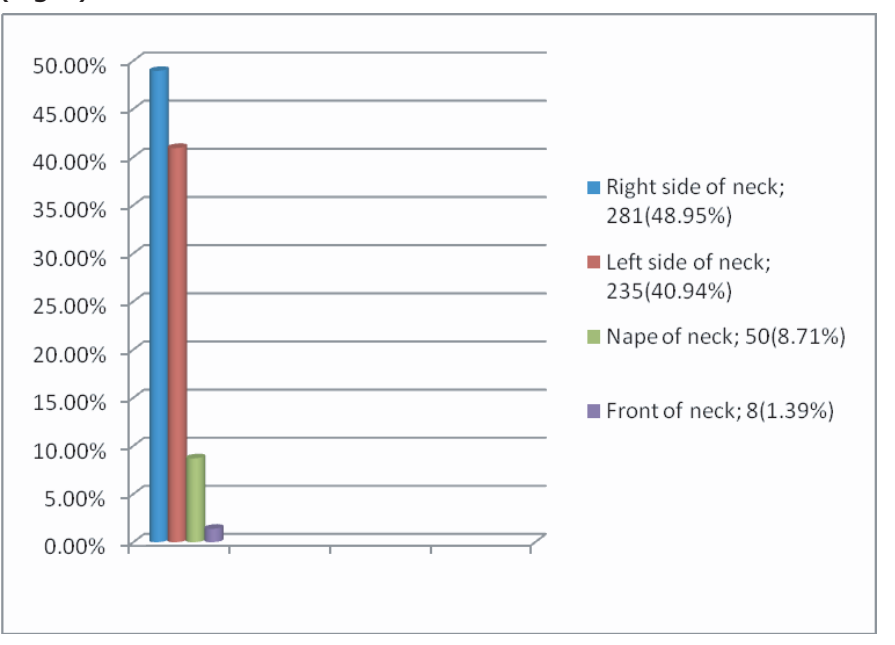

Fig-2 Position of Knot of ligature ( $n=574)$

Most of the study subjects were right handed. In this study single ligature mark has been found in $511(89.02 \%)$ cases 
followed by double ligature mark $17(2.96 \%)$ and very faint $31(5.40 \%)$. Ligature mark was completely absent in $15(2.62 \%)$ cases. The mark was continuous in $50(8.71 \%)$ and non continuous $478(83.27 \%)$ study subjects. In $520(90.59 \%)$ cases ligature was found above thyroid cartilage level, 28(4.88\%) had marks at thyroid cartilage level and $11(1.92 \%)$ had marks below thyroid cartilage level.

The mark was oblique in $509(88.68 \%)$ cases and transverse in $50(8.71 \%)$. Impression corresponding to ligature material found in $126(21.95 \%)$ cases (Table-III).

$\begin{array}{lc}\text { Table-III: Variation of ligature marks in neck ( } \mathbf{n = 5 7 4 )} \\ \text { According to loop } \\ \text { Single } \\ \text { Double } & 511(89.02 \%) \\ \text { Very faint } & 17(2.96 \%) \\ \text { Marks absent } & 31(5.40 \%) \\ \text { According to marks } & 15(2.62 \%) \\ \text { Continuous } & \\ \text { Non continuous } & 50(8.71 \%) \\ \text { Very faint } & 478(83.27 \%) \\ \text { Marks absent } & 31(5.40 \%) \\ \text { According to level } & 15(2.62 \%) \\ \text { Above thyroid cartilage } & \\ \text { At the level of thyroid cartilage } & 520(90.59 \%) \\ \text { Below level of thyroid cartilage } & 28(4.88 \%) \\ \text { Absent } & 11(1.92 \%) \\ \text { According to Position } & 15(2.61 \%) \\ \text { Oblique } & \\ \text { Transverse } & 509(88.68 \%) \\ \text { Absent } & 50(8.71 \%) \\ \text { According to ligature material imprint } & 15(2.61 \%) \\ \text { Present, corresponding to ligature material } & \\ \text { Absent } & 126(21.95 \%) \\ \text { Imprint not found } & 433(75.44 \%) \\ & 15(2.61 \%)\end{array}$

In this study complete suspension were 472 (82.23\%) victims and $102(17.77 \%)$ were partial hanging. Considering injury to neck structures stretching and elongation of neck was found in $448(78.04 \%)$ cases, haemorrhage in underlying layers of neck skin in 372(64.81\%), haemorrhage in strap muscles were seen in $162(28.22 \%)$, rupture of platysma and sternocledo mastoid muscles in $66(11.49 \%)$ cases, transverse split of carotid artery intima with extravasation of blood in $27(4.70 \%)$, rupture of vertebral arteries with intimal tear and sub intimal haemorrhage in $15(2.62 \%)$ cases, fracture of thyroid cartilage in $2(0.35 \%)$, petechial haemorrhage in epiglottis, larynx, trachea in $16(2.78 \%)$, congestion of trachea $568(98.95 \%)$ and fracture of hyoid bones in $81(14.11 \%$ ) cases (Table-IV).
Table-IV: Injury to neck structures $(n=574)$

$\begin{array}{lc}\begin{array}{l}\text { Same victim showed multiple types of injury* } \\ \text { Location and percentage }\end{array} \\ \begin{array}{l}\text { Types of neck structures injury } \\ \text { Stretching and elongation of neck }\end{array} \\ \begin{array}{lc}\text { Haemorrhage in underlying layers of neck skin } & 372(64.04 \%) \\ \text { Haemorrhage in strap muscles } & 162(28.22 \%)\end{array} \\ \begin{array}{l}\text { Rupture of platysma and sternocledomastoidmuscle } \\ \text { Transverse split of carotid artery intima with }\end{array} & 66(11.49 \%) \\ \text { extravasation of blood } & 27(4.70 \%) \\ \text { Rupture of vertebral arteries with intimal tear and } & \\ \text { sub intimal haemorrhage } & 15(2.62 \%) \\ \text { Injury to trachea, } & \text { Nil } \\ \text { fracture of thyroid cartilage } & 2(0.35 \%) \\ \text { Petechial haemorrhage in epiglottis, larynx, trachea } & 16(2.78 \%) \\ \text { Congestion of trachea } & 568(98.95 \%) \\ \text { Fracture of hyoid bones } & 81(14.11 \%)\end{array}$

Most of the victims 401 ( 69.86\%) hanged themselves at night. 545 body (94.95\%) were recovered from inside the living rooms.

\section{Discussions}

Exact number of suicidal deaths by hanging in Bangladesh are not known but in our neighboring country India, every 5 minutes a person commits suicide, 7 attempts to kill themselves forming around 100,000 suicide death per year; either by hanging or ingestion of insecticides or barbiturate tablets. ${ }^{13} \mathrm{~A}$ five year study (1998- 2002) in Turkey also showed that hanging is the commonest method of suicide in Istanbul. ${ }^{14} \mathrm{~A}$ study in Lithuania has shown that a total of 8324 suicides were committed during 1993- 1997 and 7823 between 1993-2002. Among all these registered suicides cases, hanging was the commonest method used to commit suicide. ${ }^{15}$

In this study out of 574 hanging cases, 159 (27.71\%) were male and 415 (72.29 \%) female. Among them 304( 52.96\%) were married and $270(47.04 \%)$ were unmarried. Marital disharmony/quarrel between couples was the main cause $172(29.96 \%)$ found for suicidal hanging.

In this study most of the victims $269(46.86 \%$ ) were from the age group 21- 30 years. Study has shown that people belong to this age group are also common victims of hanging in other countries. ${ }^{16-19}$ These young groups committed suicide mainly due to emotional instability, mental depression $77(13.42 \%)$, drug addiction 65(11.32\%), failure in love affairs $47(8.19 \%)$ and unwanted pregnancy $37(6.44 \%)$. In both developed and developing countries the suicide rate among young people appear to be rsing. Peer pressure and emotional issues are the triggering factors. ${ }^{20}$

Most of the victims 401(69.86\%) hanged themselves at night. 545 body $(94.95 \%)$ were recovered from inside the living rooms. 
A number of victims committed suicide at late night, inside the room where none remains to resist them from suicidal behavior. Davidson et $\mathrm{al}^{21}$ in his study had shown that home (74.1\%) was the commonly preferred place for suicidal hanging. Bowen ${ }^{22}$ in his study also showed most of suicidal hanging took place inside home.

Dopatta (orna) was the commonest 237(41.28\%) ligature material followed by jute rope $195(33.97 \%)$ and shari 42(7.32\%). Sharma et al in his study between 1997 to 2004 at Chandigarh Govt Medical College \& Hospital, India showed that chunni (orna) was the commonest(30.90\%) ligature material followed by nylon rope (18.18\%), bed sheet (16.36\%). and jute rope $(12.73 \%) .{ }^{23} \mathrm{~A}$ study in our neighboring country Nepal done by Pradhan A during January 2007 to April 2008 has shown that maximum people used rope (47.72\%) followed by shawl $(31.81 \%)$ shari $(9.09 \%)$ and woolen muffler(4.54\%). ${ }^{24}$

The victims hang themselves from ceiling fan, ceiling hook, pipe of bathroom, beams, girder etc using a chair or table or tool as the base for standing, later on push them away by feet. In the outdoor cases branch of a tree, light post etc are commonly used as the point of suspension. In western countries belt, electric cable, scarf, tie, dressing gown cord, shoe lace, curtain cord, telephone cord, shower lead etc are used as ligature materials, which are not so used in our country. ${ }^{25}$

Considering the knot, most were situated at right side of neck $281(48.95 \%)$, followed by left side $235(40.94 \%)$, at the nape of neck $50(8.71 \%)$ and in front of neck below chin $8(1.39 \%)$. Knot on right side of neck is commonly available for right hand users, who are more abundant in our country than left hander. This coincides with studies done before by O P Saini in 2005 at S $P$ Medical College at Bikener, India, which had shown that $15(45.45 \%)$ cases had knot on right side, $11(33.34 \%)$ cases had knot on left side and $7(21.21 \%)$ on other places of neck out of $33(100 \%)$ cases of hanging. ${ }^{26}$ The knot is usually present in the form of a simple slip knot to produce running noose or fixed by granny or reef knot, occasionally a simple loop is used. ${ }^{1}$

Ligature mark in the neck is the principal external sign in hanging that requires very meticulous inspection. In this study single ligature mark has been found in $511(89.02 \%)$ cases followed by double ligature mark $17(2.96 \%)$ and very faint $31(5.40 \%)$. The mark was oblique in $509(88.68 \%)$ cases and transverse in $50(8.71 \%)$. In this study the ligature mark was continuous in 50(8.71\%) and non continuous 478(83.27\%) study subjects. Impression corresponding to ligature material found in $126(21.95 \%)$ cases. The ligature mark was completely absent in $15(2.62 \%)$ cases. Any intervening object like beard, hair, neck tie, clothings if get tangles between neck and ligature material will not produce any marks on neck. Again soft broad ligature material like scarf, towel, produces faint marks. If someone is rescued soon after hanging the ligature mark may be absent ${ }^{1}$.

In this study $520(90.59 \%)$ cases had ligature above thyroid cartilage level, 28(4.88\%) had marks at thyroid cartilage level and $11(1.92 \%)$ had marks below thyroid cartilage level. This coincides with a study done by Reddy KSN, which showed that in $80 \%$ cases ligature marks situated above thyroid cartilage level between chin and and larynx, in $15 \%$ cases at the level of thyroid cartilage and in $5 \%$ cases below the cartilage. ${ }^{1}$

Considering injury to neck structures stretching and elongation of neck was found in $448(78.04 \%)$ cases. In hanging the neck is always stretched due to elasticity of neck muscles and vessels unless the body is removed soon after hanging. Haemorrhage in underlying layers of neck skin had been found in 372(64.81\%) cases, haemorrhage in strap muscles were seen in $162(28.22 \%)$, rupture of platysma and sternocledo mastoid muscles in $66(11.49 \%$ ) cases. Haemorrhage occurs due to direct trauma prodecud by ligature material and ruptured muscles indicates considerable violence, specially in long drop. Reddy in his study stated that haemorhhage may be persent in $25 \%$ cases and rupture of muscles in 5- 10\% cases, which coincides with our study. ${ }^{1}$

Transverse split of carotid artery intima with extravasation of blood were found in $27(4.70 \%)$ cases and rupture of vertebral arteries with intimal tear and sub intimal haemorrhage in $15(2.62 \%)$ cases. These also occurs due to stretching and crushing of blood vessels in long drop and prolonged hanging. Fracture of thyroid cartilage seen in $2(0.35 \%)$ cases with petechial haemorrhage in epiglottis, larynx, trachea in $16(2.78 \%)$, congestion of trachea in $568(98.95 \%)$ and fracture of hyoid bones in $81(14.11 \%)$ cases. Reddy(2004) stated fracture in $10-20 \%$ cases, Nikolic S(2003) showed fracture in $68 \%$ cases, ApurvaNandy (2000) showed in $5-10 \%$ cases, Betz $\mathrm{P}(1996)$ showed in $67 \%$ cases, Wintraub(1961) found fracture in $27 \%$ cases and Reutor(1901) stated in $60 \%$ cases. But Modi(1988) stated that fracture of hyoid bones are rare. Whereas Smith and Foddes(1955) and Mukherjee JB(1994) had never found any fracture in their study. ${ }^{27}$

Conclusion : This retrospectivemedico legal study find out various data of hanging victims of one of the largest heath care center,Dhaka Medical College, which cover a large area of population. Though multi center prospective study should be carried out to find out our real situation. 


\section{References}

01. Reddy KSN. The Essentials of Forensic Medicine \& Toxicology. Medical Book Coy, Hyderabad, India. 24 ${ }^{\text {th }}$ Ed.2005.p 286- 295.

02. Nandy A. Principle of Forensic Medicine including Toxicology. Central Book Agency, New Delhi, India. $3^{\text {rd }}$ Ed. 2010 p:517-518

03. Knight B, Pekka S. Knight's Forensic Pathology. Arnold, London. $3^{\text {rd }}$ ed.2004. p: $352-380$

04. Galgali RB , Sanjeeb R, Ashok MV, Appaya P, Srinivasan K. Psychiatric diagnosis of self poisoning Cases ; a general hospital study . Ind J Psych 1998;40(3): 254-259

05. Kandamuthan M. Preliminary findings on the Psychosocial factors for attempt of suicide in Kerala. NIMHANNS J 1998;1: 261-70

06. Mohanty S, Sagu H, Mohanty MK, Patnaik M. Suicide in India: A four year retrospective study. J Forensic Leg Med 2007; 14(2): 185-189

07. Nikolic S, Micic J, Atanasijevic T, Djokic V, Djonic D. Analysis of neck injuries in hanging. Am J for Med Path 2003; 24(2): 179-182.

08. Morild I. Fractures of neck structures in Suicidal hanging. Med Sci Law 1996; 36(1):80-84

09. Toro K, Krostof I, Keller E. Incomplete decapitation in suicidal hangingreport of a case and review of the literature. J For Leg Med 2008;15(3): 180-184

10. Brock A, Griffiths C. Trends in Suicide by method in England and Wales., 1979- 2001. Health Stat Quart 2003; $20: 7-18$

11. Gupta SC,SinghH,Psychiatric illness in Suicidal attempters. Ind J Psychiatry 1981; 23(1):69-74

12. Narang RL, Mishra BP, Nitesh M. 2000 Attempted suicide in Ludhiana, Ind J Psychiatry $2000 ; 42(1): 83-87$

13. Sanjush B, Manju PH, Yesudas KF Psychiatric diagnosis in attempted suicide. Cal Med J 2006; 4(3): e2

14. Uzun I, Buyuk Y, Gurpinar K. Suicidal Hanging : Fatalities In Istanbul Retrospective Analysis of 761 Autopsy Cases . J For Leg Med 2007; 14(7): 406-409

15. Starkuviene S, Kalediene R, Petrauskiene J. Epidemic of Suicide by hanging in Lithuania : does socio demographic status matter ? Pub Health. 2006;120(8): 769-775

16. Sharma BR, Harish D, Sharma A, Sharma S, Singh $H$. Injuries to neck structures in deaths due to constriction of neck, with a special reference to hanging. J For Leg Med 2008 ;15(5): 298- 305

17. Dixit PG, Mohinte PM, Ambade VN. Study of histopathological changes in Thyroid, salivary gland and lymph nodes in hanging. Journal of For Med \& Toxicology 2001;18:1-4

18. Sengupta BK. Studies on 101 cases of death due to hanging. JIMA 1965;3:135-140.

19. Singh A, Gorea RK, Dalal JS et al. A study of demographi variables of violent asphyxia death. Journal of Punjab Aca of For Med \& Toxicology 2003;3:2225.

20. Eddlesto M, RezviSMH,Hawton K. Deliberate Self Harm in Srlanka; an overlook tragedy in the developing world. BMJ 1998;7151: 133-135 .

21. Davidson A, Marshall TK. Hanging in Northern Ireland- A survey. Med Sci and Law 1986;26:23- 28.

22. Bowen DA. Hanging- A Review. Journal of For SciInt 1982;20:247-9.

23. Sharma BR,Harish D, Singh VP, Singh P. Ligature mark on neck: how informative ? JIAFM 2005;27(1):10-15

24. Pradhan A, Mandal BK, Tripathi CB. Hnaging: Nature of ligature material applied and type of hanging according to poit of suspension. Nepal Med Coll J. 2012;14(2):103-106.

25. Bennewith O, Gunnel D, Kapur N, Simkin S. Suicide by hanging: multi centre study based on coroners records in England. BMJ 2005; 186: 260-261
26. Saini $\mathrm{OP}$, Saini $\mathrm{PK}$, Jain $\mathrm{R}$ et.al. Position of Knot in neck and relation with working hand in cases of Hanging. IIJFMT 2005;3(1):41-43.

27. Naik SK, Patil DY. Fracture of hyoid bone in cases of asphyxia deaths resulting from constriction force round the neck. JIAFM 2005;27(3):149-153. 